\title{
Adaptação Humana ao Stress em Contextos Desportivos: Teoria, Avaliação, Investigação e Intervenção
}

\author{
Human Adaptation to Stress in Sport Contexts: Theory, Evaluation, \\ Research and Intervention
}

A. Rui Gomes ${ }^{1 *}$

NOTA DE INVESTIGAÇÃO | RESEARCH NOTE

Não existem dúvidas acerca do facto dos fatores psicológicos desempenharem um papel fundamental no modo como os atletas se adaptam ao contexto desportivo bem como acerca da influência destes fatores no rendimento desportivo que os atletas obtêm ao longo das suas carreiras (Cox, Shannon, McGuire, \& McBride, 2010; Hatzigeorgiadis, Zourbanos, Galanis, \& Theodorakis, 2011; MacNamara, Button, \& Collins, 2010). No entanto, existem muitas dúvidas acerca do modo como o "lado mental" interfere nesta adaptação e no sucesso desportivo final obtido em cada competição disputada. Uma das razões que justifica este facto prende-se com a grande dificuldade em estudar, de um modo integrado, os fatores que podem influenciar a adaptação dos atletas a situações stressantes no desporto e que podem, no final, condicionar o rendimento desportivo.

Uma das propostas conceptuais que mais tem avançado neste esforço integrado de compreender a adaptação humana em situações de stress é a Teoria Cognitiva, Motivacional e Relacional de Lazarus $(1991,1999)$. De um modo geral, a teoria propõe que a adaptação humana a situações exigentes implica que analisemos, de um modo unificado, o stress, a avaliação cognitiva e confronto (i.e., o confronto) e as emoções. Ou seja, para percebermos a razão pela qual uma dada pessoa se adapta bem ao stress, implica considerar a situação em que ela se encontra (e.g., fonte de stress), o modo como a situação é percebida pela pessoa (e.g., processos de avaliação cognitiva ao nível primário), o modo como a situação é enfrentada pela pessoa (e.g., processos de avaliação cognitiva ao nível secundário, ou confronto) e o modo como a pessoa se sente antes, durante e após a situação de mudança (e.g., emoções).

Nesta linha de pensamento, Gomes (2014) propõe o Modelo Interativo de Adaptação ao Stress, onde sugere que o entendimento da adaptação humana em situações de stress implica considerar a interação entre os processos de avaliação cognitiva e as respostas psicológicas, fisiológicas e comportamentais que conduzem, no final, a um determinado resultado, positivo ou negativo, no modo como cada pessoa lida com as exigências colocadas pelo stress. Este processo interativo é condicionado por fatores antecedentes (ao nível das características da situação e da pessoa em causa) bem como pela importância que a pessoa atribui a essa mesma situação de stress (ver Figura 1). Esta abordagem tem igualmente uma natureza transacional como a proposta de Lazarus (1991, 1999), tendo a vantagem de incluir no processo de análise uma maior complexidade nos processos de avaliação cognitiva (que podem ser de primeiro e segundo níveis) e o facto de atribuir um papel mais relevante à perceção de importância atribuída pela pessoa à situação stressante, representando a "porta de entrada" do início da adaptação ao stress. Por outro lado, o modelo fornece algumas indicações acerca do estatuto das variáveis nos planos de investigação deste fenómeno,

${ }^{1}$ Escola de Psicologia da Universidade do Minho, Braga, Portugal

* Autor correspondente: Universidade do Minho, Escola de Psicologia, Campus de Gualtar, 4710-057-Braga,

Portugal. E-mail: rgomes@psi.uminho.pt 
conferindo à avaliação cognitiva um papel mediador na relação entre a situação de stress e o resultado final e estabelece que os fatores antecedentes (e.g., características situacionais e pessoais) podem moderar a mesma relação entre a situação de stress e o resultado final. Esta distinção é importante, pois poderá ajudar perceber o modo como podem ser analisadas as relações entre as variáveis envolvidas na adaptação ao stress, estabelecendo o modo como devem ser conceptualizadas, avaliadas e testadas.

Um dos aspetos comuns, e fundamentais, a ambas as abordagens é o facto de proporem que a compreensão da adaptação ao stress implica perceber a relação entre a situação de tensão e o indivíduo. Apesar de parecer óbvia esta necessidade, a verdade é que conseguir integrar todas as dimensões envolvidas nesta relação num único estudo é uma tarefa difícil e complexa. É, por isso, que quando analisamos grande parte dos estudos efetuados sobre este tópico no domínio desportivo e que têm por base a proposta transacional de Lazarus, constatamos que tendem a estudar este fenómeno de um modo parcelar, ora focando-se nos fatores de stress (Campbell \& Jones, 2002; Fletcher, \& Hanton, 2003; McKay, Niven, Lavallee, \& White, 2008; Noblet \& Gifford, 2002), nos processos de avaliação cognitiva (Balk, Adriaanse, de Ridder, \& Evers, 2013; Nicholls, 2007; Nicholls, Polman, Morley, \& Taylor, 2009) ou nas emoções resultantes (Nicholls, Levy, Jones, Rengamani, \& Polman, 2011; Rathschlag \& Memmert, 2015), existindo menos estudos centrados na relação interativa entre todos eles (Nicholls, Perry, \& Calmeiro, 2014).

Apesar destas dificuldades, a abordagem transacional de Lazarus continua a suscitar o interesse dos investigadores e é, hoje em dia, a proposta mais utilizada em contextos desportivos quando se trata de estudar o tema da adaptação dos atletas a situações de stress (Nicholls \& Polman, 2007). Portanto, a questão que se coloca não é tanto acerca da aceitação do processo transacional e interativo da relação entre stress e indivíduo mas antes acerca do modo como poderemos estudar, de forma integrada e unitária, estes processos de adaptação.
É neste sentido que este trabalho é elaborado, propondo uma análise integrada do fenómeno da adaptação humana em situações de stress no desporto, procurando destacar não só os principais constructos psicológicos a incluir nesta análise mas fornecendo igualmente indicações sobre duas metodologias de avaliação deste fenómeno. Através de um entendimento conceptual integrado sobre a adaptação ao stress no desporto e através do uso de medidas que captem este fenómeno, poderemos avançar na procura de respostas acerca dos fatores que justificam o facto dos atletas funcionarem de um modo mais positivo que outros quando se confrontam com as exigências desportivas.

Tendo por base estes aspetos, este trabalho organiza-se em seis partes. Em primeiro lugar, analisamos as situações de stress e os seus fatores antecedentes, salientando a importância das variáveis situacionais e pessoais que podem ajudar a perceber melhor o porquê de uma dada situação de stress ter captado o interesse da pessoa em causa. Em segundo lugar, destacamos os processos de avaliação cognitiva, incluindo a importância atribuída à situação e a avaliação cognitiva de primeiro e segundo níveis. Da relação entre estes processos de primeiro e segundo níveis, descrevemos, em quarto lugar, as respostas ocorridas ao nível psicológico, fisiológico e comportamental. Em quinto lugar, damos enfase ao resultado final da adaptação ao stress, salientando a sua potencialidade inerentemente positiva ou negativa para $o$ indivíduo. Finalmente, em sexto lugar, fornecemos um conjunto de indicações finais para os estudos nesta área. Ao longo do artigo incluímos exemplos concretos de duas metodologias de avaliação da adaptação ao stress, uma de natureza qualitativa (Entrevista de Avaliação da Adaptação ao Stress) e outra de natureza quantitativa (Questionário de Avaliação da Adaptação ao Stress). Por questões de limite de espaço, não é possível incluir os dois instrumentos em versão completa, mas ambos estão disponíveis através do contacto com o autor deste artigo. 


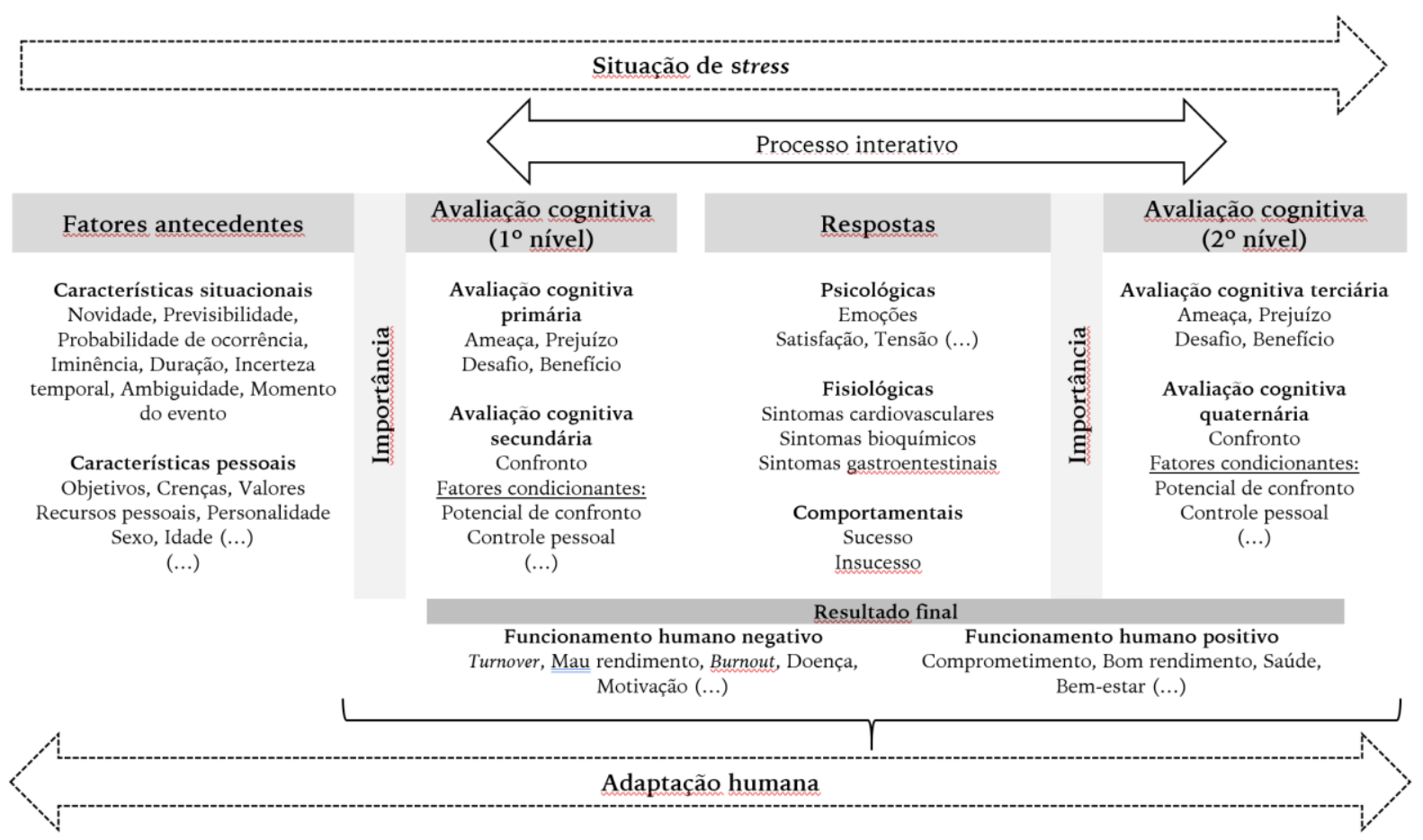

Figura 1. Modelo Interativo de Adaptação ao Stress (Fonte: Gomes, 2014)

\section{Situação de Stress e os Fatores Antecedentes}

A análise da adaptação ao stress inicia com uma compreensão das contingências em que a pessoa se viu envolvida. Ou seja, o objetivo será verificar como é que o atleta percecionou uma dada situação como stressante (ex: disputar um jogo decisivo, sofrer uma lesão grave, falhar num momento importante de um jogo, etc.). Reparese que é sempre a partir de uma situação específica de stress que é efetuada a análise do processo transacional e interativo estabelecido entre a pessoa e a circunstância em que se encontra.

Neste sentido, importa compreender a situação de stress. Neste caso, nos dois instrumentos propostos é efetuada uma avaliação de uma situação concreta de stress e, nesta sequência, todas as questões restantes reportam sempre a este acontecimento restrito e delimitado num dado período temporal (ver Quadro 1). Por exemplo, no guião de entrevista parte-se de uma análise das fontes gerais de stress sentidas pelo atleta na sua atividade desportiva para depois ser selecionada apenas uma delas (com maiores níveis de stress e de importância) para ser analisada em termos do processo de adaptação. No questionário, os atletas devem selecionar e descrever a situação que lhes gerou maior stress na carreira desportiva e devem depois responder a todo o questionário a partir dessa situação. Deste ponto de vista, os dois instrumentos aproximam-se da lógica de análise de incidentes críticos (Carver, Scheier, \& Weintraub, 1989; Folkman \& Lazarus, 1988), onde se discute o modo como os atletas percecionaram e geriram uma situação promotora de maior stress na carreira desportiva. Neste sentido, convém esclarecer que os dois instrumentos propostos podem ser aplicados nesta lógica da "maior fonte de stress na carreira desportiva" ou podem ser aplicados fazendo referência a uma fonte de stress concreta (ex: disputar um jogo decisivo) analisando-se de seguida todo o processo de adaptação. Neste último caso, existe a vantagem de analisar como diferentes atletas avaliam e reagem perante a mesma situação stressante.

Como forma de aferir se estamos perante uma situação geradora de stress e, consequentemente de esforços de adaptação, são colocadas, em ambos os instrumentos, duas questões relacionadas com o nível de stress e o nível de importância da situação em causa. O nível de importância será retomado mais à frente neste trabalho. No entanto, convém desde já esclarecer que estas duas questões ajudarão o investigador a verificar se foi ou não selecionada uma situação 
exemplificadora de stress e interesse para o atleta em causa. Ambos os domínios são respondidos pelo atleta através de itens em formato "likert" de cinco pontos. Por exemplo, no caso do stress, propõe-se uma escala de 1 ("Nenhum stress") a 4 ("Elevado stress"). Obviamente, índices de baixo stress e de importância (valores até dois nas escalas propostas) poderão não representar uma situação de elevada dificuldade para o atleta, devendo-se questionar a existência de outras situações eventualmente geradoras de maior stress e importância para o atleta.

Após a descrição da situação de stress, importa analisar os fatores que poderão condicionar a experiência de stress. Neste caso, é relevante salientar o facto da situação de stress ser dinâmica e alterar-se ao longo do tempo. Ou seja, não só as situações de stress vão sendo distintas ao longo da vida das pessoas, como a mesma situação de stress se vai alterando ao longo do processo interativo de adaptação ao stress. Neste sentido, análises absolutistas e de "tudo ou nada" ajudam pouco a compreender este fenómeno.

Assim sendo, e considerando o modelo interativo, os fatores antecedentes incluem variáveis situacionais e pessoais. As situacionais, referem-se a um conjunto de propriedades ou características que podem ajudar a perceber o que há exatamente na situação que a tornou stressante para pessoa. De facto, e como referem Lazarus e Folkman (1984), importa descrever e perceber qual a situação concreta de stress (ex: falhar em momentos decisivos de um jogo, poder sofrer uma lesão grave, etc.), mas o mais importante é procurar compreender os aspetos que tornaram a situação exigente, existindo menos indicações sobre isto em contextos desportivos (Fletcher, Hanton, \& Mellalieu, 2006; Thatcher \& Day, 2008). Neste caso, Lazarus e Folkman (1984) formularam oito propriedades (ou características) que podem transformar uma dada situação num momento potencialmente stressante: (1) novidade: até que ponto a situação de stress foi ou não experienciada pela pessoa anteriormente; (2) previsibilidade: até que ponto a situação de stress está ou não de acordo com as expectativas de ocorrência por parte da pessoa; (3) probabilidade de ocorrência: até que ponto a situação de stress é ou não provável de acontecer;
(4) iminência: até que ponto houve ou não a possibilidade de antecipar a ocorrência da situação de stress; (5) duração: até que ponto a situação de stress durou mais ou menos tempo; (6) incerteza temporal: até que ponto se sabe o exato momento da ocorrência da situação de stress; (7) ambiguidade: até que ponto existe informação clara sobre as circunstâncias da ocorrência da situação de stress; e (8) momento do evento: até que ponto estavam a acontecer outros acontecimentos stressantes no momento da ocorrência da situação de stress. A título de exemplo, consideremos o seguinte caso. Um atleta foi convidado a assinar um contrato com uma equipa profissional, passando assim a competir no nível mais exigente da sua modalidade. Este seria o nível competitivo mais elevado em que tinha participado até aí. Antes de iniciar a época, o atleta questionou-se constantemente se teria feito uma boa opção em assinar o contrato e estava cada vez mais descrente acerca das suas capacidades para ser bem-sucedido a este nível. Ainda antes da época começar, sentiu-se bastante tenso e frustrado por não saber o que fazer e começou a ter pensamentos acerca da desistência da atividade desportiva. Neste caso, pode dizer-se que a natureza contingencial se alterou na vida do atleta e despoletou uma situação de stress, essencialmente marcada pelo seu carácter de novidade bem como por alguma imprevisibilidade e ambiguidade.

Em suma, a análise das oito propriedades da situação de stress permite-nos compreender em maior detalhe o enredo da contingência em que uma dada pessoa se viu envolvida. Todos estes aspetos foram contemplados nos dois instrumentos propostos, estando também incluídos nos fatores situacionais antecedentes do modelo interativo (ver Figura 1). No Quadro 1 , são incluídas questões que avaliam as oito propriedades da situação de maior stress.

Do ponto de vista pessoal, são vários os fatores que podem condicionar a adaptação ao stress. A título de exemplo, os objetivos, as crenças e os valores da pessoa podem influenciar o modo como perceciona a situação de stress (Lazarus, 1999). Por exemplo, se o atleta assumir a crença que "tem de fazer sempre tudo bem 
feito" poderá ter uma maior dificuldade em lidar com os erros durante o jogo e tornar os momentos decisivos ocorridos durante a competição mais stressantes. Também os recursos pessoais que o atleta tem ao seu dispor (ex: baixos ou altos níveis de apoio social, condições materiais ou financeiras, etc.) e a sua própria personalidade (ex: tendência para a depressão, rigidez de pensamento, etc.) poderão alterar o modo como a situação é percecionada (Lazarus, 1995). De igual modo, aspetos demográficos como o sexo, a idade, o estado civil, a experiência na situação de stress, o nível de competência na atividade, entre outros, podem condicionar a análise e adaptação à situação de stress (Calmeiro, Tenenbaum, \& Eccles, 2014; Kaiseler, Polman, \& Nicholls, 2013; Shirom, Gilboa, Fried, \& Cooper, 2008).

Estes fatores pessoais são englobados no Modelo Interativo de Adaptação do Stress (ver Figura 1), mas não são avaliados nos dois instrumentos de avaliação, uma vez que a sua natureza específica e multivariada não permite antecipar todos as dimensões a incluir nas duas medidas. Neste sentido, caso o investigador tenha interesse em analisar o papel destas variáveis na adaptação ao stress, deverá incluir instrumentos específicos para tal (ex: medidas de personalidade, apoio social, etc.).

\section{Processos de Avaliação Cognitiva}

Os processos de avaliação cognitiva representam um elemento chave na compreensão da adaptação ao stress (Lazarus \& Folkman, 1984). Ou seja, o modo como as pessoas avaliam e se confrontam com as exigências colocadas pela situação de stress pode fazer a diferença entre uma adaptação positiva ou negativa ao acontecimento stressante (Wolf, Evans, Laborde, \& Kleinert, 2015). Para o Modelo Interativo de Adaptação ao Stress, a "porta de entrada" da avaliação e confronto com o stress é conferido pela perceção de importância, ou seja, pelo valor e significado pessoal que a pessoa atribui à situação de stress (ver Figura 1). Como foi referido anteriormente, a perceção de importância e a avaliação dos níveis de stress gerados pela situação servem para avaliar até que ponto o atleta selecionou uma situação relevante, do ponto de vista pessoal e desportivo.
Repare-se que apenas situações importantes para o atleta poderão desencadear um esforço de adaptação ao stress, sendo este um dos objetivos da utilização dos dois instrumentos propostos neste trabalho.

\section{Primeiro Nível da Avaliação Cognitiva}

A partir do momento em que estamos perante uma situação de stress e importante para o atleta, passa-se à análise dos processos de avaliação cognitiva, ao nível primário e secundário, designados no modelo interativo como "primeiro nível” da avaliação cognitiva (ver Figura 1). No que se refere à avaliação cognitiva primária, a pessoa analisa o que "está em causa nesta situação", aferindo o significado pessoal da situação para o seu bem-estar, podendo daqui resultar quatro tipos de avaliações: (a) ameaça: significa que a pessoa avaliou a situação como potencialmente negativa e geradora de dano; (b) perda/prejuízo: significa que a pessoa avaliou a situação como tendo num dano efetivo para si própria; (c) desafio: significa que a pessoa avaliou a situação como podendo ter um potencial ganho, isto apesar de reconhecer o seu grau de dificuldade; e (d) benefício: significa que a pessoa avaliou a situação como podendo realmente gerar ganhos efetivos (Lazarus, 2000a,b). Mais à frente, analisaremos as respostas que podem decorrer da exposição e confronto com a situação de stress. No entanto, convém desde já referir que processos de avaliação cognitiva mais negativos (e.g., ameaça e perda/prejuízo) estarão mais associados a respostas negativas (ex: ansiedade, tristeza, culpa, etc.), enquanto que processos de avaliação cognitiva mais positivos (e.g., desafio e benefício) estarão mais associados a respostas positivas (ex: alegria, excitação, orgulho, etc.) (Lazarus, 1991). Nos dois instrumentos propostos são avaliados estes dois tipos de processos de avaliação cognitiva, nomeadamente a ameaça e o desafio (ver Quadro 1).

No processo de adaptação, após a avaliação primária segue-se a avaliação cognitiva secundária (ver Figura 1). Neste caso, analisa-se os esforços de adaptação à situação de stress, caracterizando-se pelas estratégias de confronto utilizadas para lidar com as dificuldades e exigências sentidas (Lazarus 1991, 1999). 
Assim sendo, ambos os instrumentos de avaliação analisam aquilo que o atleta pensou e fez quando se confrontou com a situação de stress (ver Quadro 1). As respostas obtidas a esta questão irão permitir a análise da(s) estratégia(s) utilizadas pelo atleta na situação de stress, sendo importante interpretá-las do ponto de vista conceptual. A este nível, é habitual verificarmos uma divisão entre as estratégias de confronto centradas na resolução de problema, sendo usadas quando a pessoa procura solucionar ou alterar a situação de stress, e na regulação emocional, referindo-se aos esforços da pessoa para reduzir ou gerir o mal-estar emocional e psicológico que está associado à situação de stress (Folkman \& Lazarus, 1985). Apesar da aceitação praticamente unânime desta diferenciação, a verdade é que as tipologias de estratégias de confronto abundam na literatura. A título meramente ilustrativo, Endler e Parker (1990) efetuaram uma distinção entre as estratégias centradas na tarefa, na emoção e no evitamento da situação. Já os estudos levados a cabo por Charles Carver no desenvolvimento do "COPE" permitiram a discriminação de, pelo menos, catorze estratégias distintas de confronto (Carver \& Scheier, 1985; Scheier \& Carver, 1988).

A tipologia de estratégias de confronto a adotar pelo investigador no tratamento da informação recolhida com os instrumentos que propomos neste trabalho pode ser algo diversa, consoante a sua orientação conceptual, extravasando o âmbito deste trabalho analisar cada uma delas. No entanto, os investigadores interessados neste tema devem estar sensibilizados para interpretar as respostas do atleta em função de um determinado modelo de análise. Assim sendo, os instrumentos propostos neste trabalho propõem uma divisão entre quatro domínios de confronto: (a) as estratégias centradas na resolução do problema (avaliandose o confronto ativo e o aumento do esforço); (b) as estratégias centradas na regulação da emoção, numa vertente mais ativa (reavaliação positiva com aceitação da situação e autocontrole); (c) as estratégias centradas na regulação da emoção, numa vertente mais passiva (negação e autoculpabilização); e (d) as estratégias centradas no apoio social (emocional e instrumental). A escolha destas dimensões de confronto segue a divisão central entre estratégias centradas no problema e na emoção (Folkman \& Lazarus, 1985), dividindo-se também as estratégias de regulação emocional em ativas (onde a pessoa procura lidar de forma positiva com as emoções resultantes da situação de stress) e em passivas (onde a pessoa evita a situação de stress). Esta divisão é fundamental, uma vez que existem indicações da literatura que sugerem que o uso de estratégias mais passivas traduzem-se em efeitos mais negativos para a pessoa, em termos da sua saúde e bem-estar, bem como em pior ajustamento ao stress (Coyne \& Racioppo, 2000). A quarta área de confronto, relaciona-se com o uso do apoio social, efetuando-se, neste caso, uma avaliação do seu uso por razões mais emocionais (i.e., procurar a compreensão e empatia de pessoas importantes) e por razões mais instrumentais (i.e., procurar o apoio de pessoas que possam ajudar a resolver a situação de stress). Uma vez mais, estes domínios emergem como fundamentais na avaliação do confronto (Carver \& Scheier, 1985; Scheier \& Carver, 1988). De modo a obter-se uma ideia o mais alargada possível da multiplicidade de estratégias de confronto, foram incluídas nos instrumentos duas possibilidades de gestão da situação de stress em cada dimensão avaliada, perfazendo as oito estratégias de confronto descritas acima. Convém aqui esclarecer que esta avaliação específica das oito estratégias de confronto está disponível no Questionário de Avaliação da Adaptação ao Stress mas podem também ser usadas na entrevista de Avaliação da Adaptação ao Stress, quando o investigador opta pelo seu uso qualitativo e quantitativo.

\section{Fatores condicionadores do confronto.}

A opção por uma determinada estratégia de confronto para lidar com a situação de stress pode implicar vários fatores influenciadores. Não é possível analisarmos todos em detalhe, nem tao pouco incluir o conjunto destes fatores $s$ nos instrumentos de avaliação. Tendo por base a abordagem transacional e o modelo interativo que serviram de base à construção dos instrumentos, foram incluídos alguns destes fatores para uma avaliação mais detalhada. 
Assim sendo, a escolha da possível estratégia de confronto implica que o indivíduo analise quatro aspetos distintos: (a) responsabilidade: trata-se de saber quem é o responsável pela situação em que a pessoa se encontra, podendo esta ser atribuída ao próprio ou aos outros; (b) potencial de confronto: trata-se de saber quais os recursos que a pessoa julga possuir para gerir as exigências da situação; (c) perceção de controle: trata-se de saber qual o nível de controle que a pessoa sente face à situação de stress; e (d) expectativas futuras: trata-se de saber até que ponto as coisas podem mudar para melhor ou para pior, tornando a situação mais ou menos congruente com os objetivos pessoais (Gomes, 2011, 2014; Lazarus, 1991). Neste último caso, a análise do comprometimento dos objetivos pode ser efetuada não apenas numa perspetiva de médio e longo prazos (e.g., expectativas futuras) mas também numa perspetiva de curto prazo, avaliando-se o comprometimento imediato dos objetivos estabelecidos pelo atleta. Todos estes aspetos estão incluídos nas medidas de avaliação (ver Quadro 1).

Tal como na avaliação cognitiva primária, a resposta a estas questões pode ter um impacto emocional no indivíduo, tanto ao nível positivo como negativo (Gomes, 2011, 2014; Lazarus, 1991). Destes quatro domínios, a análise da perceção de controle e do potencial de confronto parecem-nos particularmente relevantes, pois indicam-nos o que a pessoa poderá (ou não) fazer perante a situação de stress. É neste sentido que estes dois fatores mereçam particular destaque nas avaliações cognitivas secundárias e quaternárias do Modelo Interativo de Adaptação ao Stress (ver Figura 1). Ou seja, estes dois fatores implicam que o indivíduo analise o grau de controle pessoal face à situação de stress e se possui recursos de confronto suficientes para lidar com essa mesma situação, procurando responder à questão "existe alguma coisa que eu posso fazer para lidar com este problema?".

A resposta a esta questão é mais um indicador no processo de interligação entre a situação de stress, a avaliação cognitiva primária e as estratégias de confronto (dimensões centrais no modelo transacional e no modelo interativo), permitindo aferir o modo como a pessoa procura adaptar-se a essa situação. Uma das vantagens desta análise integrada, relaciona-se com a possibilidade de verificarmos "de que modo" e "em que circunstâncias específicas" os atletas optam por determinada estratégia de confronto.

Ainda nos fatores condicionadores das estratégias de confronto, são avaliadas mais duas facetas sobre a sua utilização (Dugdale, Eklund, \& Gordon, 2002; Pensgaard \& Duda, 2002). Por um lado, até que ponto a(s) estratégia(s) de confronto foram eficazes e produziram os resultados desejados pelo atleta e até que ponto esta resposta foi automática ou implicou um esforço deliberado de resolução, por parte do atleta (ver Quadro 1).

No que se refere à eficácia das estratégias de confronto, alguns aspetos merecem particular reflexão. A este nível, durante muitos anos existiu uma tendência na literatura para considerar as estratégias de resolução de problema como mais adaptativas e funcionais do que as estratégias de regulação emocional (Carver et al.,1989). No entanto, esta ideia não encontra evidência empírica, existindo indicações de que as estratégias centradas na regulação emocional (ex: ventilar emoções) podem, em determinadas situações, ser efetivas na gestão de stress (Pensgaard \& Duda, 2002).

Neste sentido, coloca-se a questão de saber como avaliar se uma estratégia de confronto é ou não eficaz (ou adaptativa). Neste caso, o fator chave prende-se com a capacidade de controle percebida pela pessoa relativamente à situação de stress, parecendo que quanto mais baixa é esta capacidade, menor será a possibilidade de utilizar estratégias de confronto centradas na resolução do problema. Esta dimensão é avaliada em ambos os instrumentos, referindo-se ao controle pessoal sobre a situação de stress. Aplicando esta ideia aos contextos desportivos, podemos ter uma situação em que o atleta é confrontado com um problema cujo grau controle é mínimo ou inexistente (ex: não ser convocado para uma determinada competição importante). Neste caso, pode ser mais importante e aconselhável para o atleta partilhar a sua tristeza com outras pessoas (regulação emocional), do que procurar imediatamente, e de forma pouco controlada, obter esclarecimentos por parte do treinador 
(resolução do problema), uma vez que essa opção poderá ser prejudicial no futuro. No entanto, um outro critério fundamental a considerar na avaliação da eficácia das estratégias de confronto, prende-se com as vantagens a curto prazo e a longo prazo na sua utilização podendo, neste caso, utilizar-se como indicadores $\mathrm{o}$ comprometimento dos objetivos e as expectativas futuras, também incluídas nos dois instrumentos de avaliação (ver Quadro 1). Assim, voltando ao exemplo anterior, a curto prazo poderá ser mais adequado para o atleta partilhar as emoções negativas com outras pessoas (regulação emocional) e a longo prazo procurar perceber junto do treinador aquilo que precisa de melhorar ou alterar, de modo a poder ser convocado em provas futuras (resolução do problema).

\section{Segundo Nível da Avaliação Cognitiva}

A possibilidade da situação de stress não representar um acontecimento único, específico e restrito no tempo, levanta a necessidade de considerarmos na análise do processo de adaptação o segundo nível da avaliação cognitiva (ver Figura 1). Neste caso, os processos de avaliação cognitiva e confronto ao nível terciário e quaternário visam obter uma análise mais completa da adaptação a situações de stress, uma vez que não é evidente que o confronto com o stress finalize após os processos de avaliação cognitiva e confronto de primeiro nível. Isto significa que podem existir circunstâncias onde exista a necessidade de desenvolver novos esforços de confronto após a avaliação cognitiva secundária, nomeadamente quando a situação final não é a mais ajustada ou desejável para a pessoa em causa. Dito por outras palavras, quando a situação de stress não é resolvida de modo aceitável pela pessoa (avaliação cognitiva secundária), podem ser gerados novos processos de avaliação e confronto que possibilitem obter uma adaptação mais conveniente e desejável.

Seguindo esta linha de pensamento, alguns autores propõem dois tipos de avaliação cognitiva adicionais: a terciária e quaternária (Fletcher \& Fletcher, 2005). Assim, no primeiro caso, importa analisar como é que a situação está a ser avaliada pela pessoa e, no segundo caso, importa analisar como é que está a ser confrontada pela pessoa (Gomes, 2014). Dito de um modo mais simples, as avaliações cognitivas terciária e quaternária não retiram a importância às avaliações cognitivas primária e secundária, procurando antes complementar o processo de adaptação, analisando o modo como o atleta reage e se comporta face à possibilidade dos stressores se manterem na situação de adaptação. Repare-se que estes processos de segundo nível só fazem sentido de ser analisados, caso a situação de stress não finalize após os esforços cognitivos de primeiro nível e se a mesma se mantiver como relevante e significativa para a pessoa. Isto significa, uma vez mais, que a perceção de importância representa a "porta de entrada" dos processos de avaliação cognitiva de segundo nível (ver Figura 1).

A título de exemplo, voltemos à situação do atleta que experiencia stress devido ao facto do seu treinador não o ter convocado para os últimos jogos que a sua equipa disputou. Seguindo o modelo interativo na sua totalidade (ver Figura 1), o atleta avaliou a situação como relevante para si ("importância"), sentindo-se algo ameaçado ("avaliação cognitiva primária") pelo facto de estar fora das opções de jogo do seu treinador. Quando verificou que voltou a não convocado para o jogo seguinte, experienciou raiva face ao tratamento recebido ("resposta psicológica"), diminuição do sono e do apetite ("respostas fisiológicas") e acabou por faltar a um dos treinos na semana seguinte ("resposta comportamental"). Como forma de lidar com a situação, procurou desabafar com os seus amigos e familiares ("avaliação cognitiva secundária, com confronto centrado no apoio social, tipo emocional) e depois procurou esclarecer a situação com o treinador ("avaliação cognitiva secundária, com confronto centrado na resolução do problema"). O atleta achou por bem discutir este assunto com o seu treinador, pois achou que poderia apresentar argumentos que demonstrariam que merecia mais oportunidades de jogar ("potencial de confronto e perceção de controle" da avaliação cognitiva secundária"). Durante a conversa, o treinador comunicou-lhe que a decisão das convocatórias era da sua responsabilidade e que o atleta não era chamado para competir pois não estava a render tanto 
como os seus colegas. No final da conversa, o atleta continuou a sentir-se injustiçado e, por isso, a raiva manteve-se como o estado emocional mais prevalente. No entanto, sentiu que valeu a pena ter tido a conversa com o seu treinador ("eficácia do confronto da avaliação cognitiva secundária") pois esclareceu um pouco mais o problema. Mas, na verdade, mantinha-se o problema: o treinador não iria passar a convocálo para os jogos seguintes só porque eles tiveram esta conversa.

Será que o processo de adaptação terminou aqui? Não necessariamente. De facto, o atleta sentia que esta situação continuava a ser relevante para ele ("importância") e que necessitava de ser resolvida. Nos dias seguintes, o atleta acentuou um pouco mais o seu sentimento de ameaça mas passou também a sentir-se desafiado pela situação de stress ("avaliação cognitiva terciária") pois passou a considerar que poderia alterar o estado em que se encontrava ("potencial de confronto e perceção de controle" da avaliação cognitiva quaternária"). Com isso, o atleta passou a treinar mais e melhor, de modo a provar ao seu treinador que era realmente uma injustiça não ser convocado para os jogos ("avaliação cognitiva quaternária, com confronto centrado na resolução do problema"). Após um certo período de tempo em que a qualidade de treino melhorou, o treinador acabou por convocá-lo novamente para os jogos e, inclusivamente, passou a ser utilizado durante estas situações ("resultado final com funcionamento humano positivo").

Considerando este exemplo, pode dizer-se que existem vantagens em incluir na análise da adaptação ao stress os processos de avaliação cognitiva de segundo nível. De facto, ao continuarmos o processo de análise da situação de ajustamento ao stress, após o atleta ter tido a primeira conversa com o seu treinador (cujo resultado não foi o desejável para ele), foi possível verificarmos que no final produziu-se um desfecho positivo, em termos do funcionamento humano. Ao estendermos a análise do stress aos processos terciário e quaternário da avaliação cognitiva, pode-se obter uma melhor compreensão da adaptação ao stress, compreendendo-o na sua natureza mais original: um processo dinâmico, volátil e frágil, cujo desfecho depende de um conjunto de fatores com natureza e relação complexas.

Em suma, a vantagem de incluirmos os processos de avaliação cognitiva aos níveis terciário e quaternário, prende-se com a possibilidade de aferirmos eventuais diferenças nos processos de reação e ajustamento às situações de stress, captando-se assim verdadeiramente a natureza dinâmica do processo de adaptação. Neste sentido, e apenas para o guião de entrevista, foram incluídas questões para avaliar a importância da manutenção da situação de stress, a ameaça, o desafio, o potencial de confronto, a perceção de controle, as estratégias de confronto e a eficácia do confronto. No entanto, convém realçar que efetivamente só faz sentido explorar o processo de adaptação nos níveis terciário e quaternário, caso a situação se mantenha por resolver, após os esforços de adaptação de primeiro nível. Dada a semelhança entre estas questões e as anteriormente formuladas para o primeiro nível da avaliação cognitiva, não estão descritas questões específicas no Quadro 1. Por outro lado, no questionário proposto não é avaliado este segundo nível da avaliação cognitiva. Esta opção não se deve à pouca importância destes fatores na adaptação humana a situações de stress mas antes ao facto do instrumento ter sido desenvolvido para avaliar o episódio de stress de um modo integrado e único. Neste sentido, torna-se difícil explicar e justificar a inclusão dos processos de avaliação cognitiva de segundo nível, que poderiam ser facilmente confundidos com os de primeiro nível (ver Figura 1). Assim sendo, caso o investigador esteja interessado em avaliar adaptações a situações de stress que se mantêm ao longo do tempo, pode aplicar novamente o questionário, referindo-se à mesma situação avaliada anteriormente. Isso permitir-lhe-á compreender a evolução da situação de stress e o impacto final em termos do funcionamento humano.

\section{Respostas na Adaptação ao Stress}

Tal como referido anteriormente, a adaptação ao stress resulta de uma análise integrada entre a situação stressante, a avaliação cognitiva de primeiro e segundo níveis e as respostas ocorridas 
que, em conjunto, ditarão um resultado final. Apesar de distinguirmos todos estes fatores por uma questão de explicitação da sua importância no processo de adaptação, a verdade é que na prática eles interagem de forma constante e influenciam-se mutuamente ao longo deste processo. Seja como for, em termos de respostas à situação de stress, o Modelo Interativo de Adaptação ao Stress propõe uma diferenciação das respostas ao nível psicológico (ex: tristeza ou alegria, motivação ou desmotivação, comprometimento ou desinvestimento, satisfação ou insatisfação), ao nível fisiológico (respostas cardiovasculares, bioquímicas e gastrointestinais) e ao nível comportamental (ex: sucesso ou insucesso a lidar com a situação de stress) (ver Figura 1).

Convém não confundir as respostas dos atletas perante a situação de stress, com o resultado final do processo de adaptação a essa mesma situação, que abordaremos mais à frente neste artigo. Ou seja, no primeiro caso, estamos a analisar o conjunto das respostas que emergem durante o confronto com a situação de stress, que podem, no final, resultar numa adaptação mais ou menos positiva. Como vimos anteriormente, um atleta pode começar por avaliar a situação de stress como ameaçadora (resultando daí emoções negativas) mas após verificar que foi eficaz a lidar com essa situação, pode acabar por experienciar emoções positivas no final da situação de stress. Neste sentido, torna-se importante questionar o atleta acerca do modo como se foi sentindo ao longo do processo de adaptação às exigências enfrentadas, resultando daqui a natureza eminentemente dinâmica e individualizada da adaptação ao stress. Isto mesmo é reconhecido no modelo interativo, ao propor-se a seta de duplo sentido entre os processos de avaliação cognitiva e as respostas à situação de stress (ver Figura 1).

Em suma, o interesse em analisar de forma diferenciada as respostas dos atletas face à situação de stress prende-se com o facto do significado atribuído a esta situação ter uma influência nas suas respostas emocionais, cognitivas e comportamentais (Folkman \& Lazarus, 1980; Lazarus \& Folkman, 1984). Por exemplo, Rotella e Lerner (1993) sugerem que a avaliação cognitiva afeta não apenas a perceção sobre o quanto uma determinada situação é stressante, mas também altera as respostas emocionais e comportamentais. Por isso, Lazarus (2000a) afirma que tanto o confronto como a avaliação cognitiva, que está subjacente ao processo de confronto, medeiam o modo como a pessoa reage emocionalmente às situações de stress.

Assim sendo, para a avaliação das respostas à situação de stress são colocadas em ambos os instrumentos questões relacionadas com as reações psicológicas, físicas (e não fisiológicas devido à maior complexidade da avaliação dos vários indicadores aqui envolvidos), comportamentais e emocionais. Esta última questão, procura discriminar melhor as reações emocionais face à situação de stress, podendo ajudar a compreender, de um modo mais exato, se estaremos perante um processo de adaptação em sentido positivo (onde predominam emoções como o alívio, a esperança, o orgulho e a alegria) ou em sentido negativo (onde predominam emoções como a ansiedade, a raiva, a tristeza, o medo, a culpa e a vergonha). A definição destas emoções a avaliar nos dois instrumentos, seguiu indicações gerais fornecidas por Lazarus (2000b), acerca das emoções gerais e específicas ao desporto, bem como adaptações de instrumentos de avaliação das emoções em contextos de rendimento desportivo (Jones, Lane, Bray, Uphill, \& Catlin, 2005). Tal como na avaliação das estratégias de confronto, convém esclarecer que a avaliação das emoções é efetuada no Questionário de Avaliação da Adaptação ao Stress mas pode também ser avaliada na entrevista de Avaliação da Adaptação ao Stress se o investigador optar pelo seu uso qualitativo e quantitativo. 
Quadro 1

Exemplo de Questões Utilizadas na Avaliação da Adaptação ao Stress

Situação de stress

Descrição da situação

De todas estas fontes de stress que estivemos a falar, seria possível escolher aquela que lhe causou maiores níveis de pressão e stress? Por favor, pense em todas as situações e escolha aquela que foi causadora de maior pressão e stress. Se necessitar, posso recordar-lhe as situações que me acabou de descrever.

De 0 a 4, qual o nível de stress que lhe gerou esta situação? Por favor, diga-me a sua resposta usando esta escala:

Valor 0 corresponde a nenhum stress; Valor 1 corresponde a pouco stress; Valor 2 corresponde a moderado stress; Valor 3 corresponde a bastante stress; Valor 4 corresponde a elevado stress

\footnotetext{
Propriedades da situação de maior stress

Fatores Antecedentes da Adaptação ao Stress

Foi a primeira vez que lhe aconteceu a situação de stress ou já lhe tinha acontecido antes? Quando? Acha que isso contribuiu para aumentar o stress que sentiu?

Esperava que lhe acontecesse a situação de stress? Porquê? Acha que isso contribuiu para aumentar o stress que sentiu?

Até que ponto a situação de stress é habitual acontecer? Era uma situação provável ou inesperada? Porquê? Acha que isso contribuiu para aumentar o stress que sentiu?

Teve tempo de se preparar para a situação de stress? Se sim, quanto tempo antes antecipou a situação? Acha que isso contribuiu para aumentar o stress que sentiu?

Quanto tempo durou a situação de stress? Quando começou e acabou? Acha que o tempo de duração contribuiu para aumentar o stress que sentiu?

Estava à espera que a situação de stress lhe acontecesse naquele exato momento? Porquê? Acha que isso contribuiu para aumentar o stress que sentiu?

Até que ponto sentiu que tinha informação ou conhecimentos suficientes acerca da situação? Porquê? Acha que isso contribuiu para aumentar o stress que sentiu?

Aconteceram na sua vida outras situações de stress quando se confrontou com esta situação de stress? Se sim, quais? Acha que isso contribuiu para aumentar o stress que sentiu?
}

Perceção de importância

Até que ponto esta situação que lhe causou stress era importante para si? Se sim, explique-me porque era importante para si esta situação.

Perceção de ameaça

Como encarou a situação de stress naquele momento? Foi algo de negativo/ameaçador? Porquê?

Perceção de desafio

Como encarou a situação de stress naquele momento? Foi algo de positivo/desafiador? Porquê?

Estratégias de confronto

Quando se deparou com a situação, o que pensou? O que procurou fazer?

Potencial de confronto

Quando se deparou com a situação de stress, até que ponto sentiu que conseguiria resolver as exigências que lhe foram colocadas? Pode dar-me exemplos por favor?

Perceção de controle

Quando se deparou com a situação de stress, até que ponto sentiu que a podia alterar ou mudar ou sentiu que havia pouco ou nada a fazer? Ou seja, até que ponto sentiu que dependia ou não de si alterar a situação? Porquê?

Eficácia do confronto

Até que ponto aquilo que procurou fazer na altura para lidar com a situação de stress foi eficaz ou produziu o resultado que esperava? Se sim, de que modo foi eficaz?

Automatismo do confronto

Até que ponto teve de refletir e pensar sobre o que fazer para lidar com a situação de stress? Ou seja, aquilo que fez foi algo que lhe "saiu de um modo automático" ou teve de pensar muito sobre o que podia fazer?

Comprometimento dos objetivos

Até que ponto a situação de stress colocou em causa os objetivos que tinha estabelecido naquele momento? Se sim, de que modo?

Expectativas futuras

Na altura, achou que a situação de stress poderia fortalecer ou prejudicar os seus objetivos futuros? De que modo?

Responsabilidade

Até que ponto achou que a situação de stress em que se encontrava era da sua responsabilidade ou o que lhe aconteceu deveu-se à ação/responsabilidade de outras pessoas? Porquê?

\begin{tabular}{|c|}
\hline Respostas na Adaptação ao Stress \\
\hline $\begin{array}{l}\text { Respostas psicológicas } \\
\text { Como se sentiu do ponto de vista psicológico e emocional? Pode dar-me exemplos? }\end{array}$ \\
\hline $\begin{array}{l}\text { Respostas físicas } \\
\text { Como se sentiu do ponto de vista físico? Sentiu algumas reações do ponto de vista corporal? Pode dar-me exemplos? }\end{array}$ \\
\hline $\begin{array}{l}\text { Respostas comportamentais } \\
\text { E em termos do seu comportamento, sentiu alterações no seu modo de funcionamento? Pode dar-me exemplos? }\end{array}$ \\
\hline $\begin{array}{l}\text { Respostas emocionais } \\
\text { Que tipo de emoções e sentimentos teve durante a situação de stress? Consegue-me indicar o tipo de emoções que sentiu durante toda a situação } \\
\text { de stress? }\end{array}$ \\
\hline Resultado Final da Adaptação ao Stress \\
\hline $\begin{array}{l}\text { Resultado emocional } \\
\text { Que tipo de emoções e sentimentos teve após a situação de stress? Consegue-me indicar o tipo de emoções que sentiu no final de toda a situação } \\
\text { de stress? }\end{array}$ \\
\hline $\begin{array}{l}\text { Resultado na satisfação } \\
\text { No final da situação de stress, até que ponto ficou satisfeito(a)? }\end{array}$ \\
\hline $\begin{array}{l}\text { Resultado no rendimento } \\
\text { No final da situação de stress, até que ponto sentiu que esta situação influenciou o seu rendimento desportivo? Foi uma influência positiva ou } \\
\text { negativa no seu rendimento? }\end{array}$ \\
\hline
\end{tabular}




\section{Resultado Final da Adaptação ao Stress}

A análise do processo de adaptação ao stress termina com uma abordagem aos efeitos da situação enfrentada pela pessoa, procurando-se recolher indicadores que sugiram estarmos perante uma adaptação positiva (onde predominam consequências benéficas) ou uma adaptação negativa (onde predominam consequências prejudiciais). Esta avaliação focase em três domínios distintos: (a) nas emoções resultantes, que são avaliadas de forma semelhante à avaliação das emoções nas respostas à situação de stress; (b) na satisfação da pessoa com a situação final, após todos os esforços efetuados para lidar com o episódio de stress; e (c) na influência da situação de stress no rendimento desportivo final. Estes três domínios são avaliados nos dois instrumentos propostos (ver Quadro 1).

Uma vez mais, convém salientar a diferenciação de consequências ocorridas durante a situação de stress (avaliadas nas "respostas" do modelo interativo) e as consequências finais ocorridas após a situação de stress (avaliadas no "resultado final" do modelo interativo). De facto, pode acontecer que as respostas durante a situação de stress assumam um carácter eminentemente negativo (ex: ansiedade, tensão muscular, sentimento de insucesso face à situação), mas após vários esforços para lidar com a situação (avaliação cognitiva ao nível secundário e ao nível quaternário) pode inverterse a situação e levar a um resultado final com impacto positivo no funcionamento do atleta. Neste sentido, convém diferenciar as respostas na situação de stress e o resultado final da situação de stress para o funcionamento do atleta.

\section{Implicações para a Intervenção e Investigação}

A compreensão dos processos de adaptação humana em situações de stress, seja ou não em contextos desportivos, tem implicações para a intervenção e investigação psicológicas.

No que se refere à intervenção, um dos objetivos relaciona-se com a promoção de processos mais ajustados de ajustamento ao stress e de funcionamento ótimo nessas situações. Este aspeto é tanto mais relevante quando pensamos no desporto, uma vez que se trata de um contexto potencialmente promotor de elevada pressão e stress nos atletas (Balk et al., 2013; Nicholls et al., 2011). Por isso, a questão que se coloca é como é que as abordagens transacional e interativa expostas neste trabalho podem ajudar o psicólogo do desporto a intervir nestes casos. A resposta tem tanto de óbvio como de complexo. O óbvio prende-se com a possibilidade em admitirmos que sempre que uma ou mais dimensões dos modelos discutidos anteriormente está condicionada no atleta, poderá estar aí a razão pela qual respondeu mais negativamente à fonte de stress e, com isso, existiu um pior ajustamento à situação em causa. O complexo prende-se, uma vez mais, com o facto dos fatores apresentados não funcionarem isoladamente mas antes de modo interativo, dinâmico e individualizado.

Independentemente destas questões conceptuais, do ponto de vista prático, estas abordagens fornecem ao psicólogo do desporto informação relevante para a sua intervenção.

Ao nível dos fatores antecedentes, é importante compreender se alguns aspetos pessoais ou situacionais estão a condicionar a experiência de stress. Por exemplo, uma análise das crenças do atleta sobre a sua atividade desportiva ajuda frequentemente a perceber a sua reação negativa ao stress. Pensamentos absolutistas, do tipo "tudo ou nada", promovem leituras distorcidas da situação, fazendo o atleta acreditar que se tem sucesso num dado jogo é um excelente atleta (e pessoa) e se o inverso suceder isso fará dele um atleta (e pessoa) débil e incompetente. Do ponto de vista situacional, a análise das oito propriedades do stress podem ser muito úteis para ajudar o atleta a lidar melhor com o stress. Neste caso, ao sabermos que um dado problema pode estar relacionado com a imprevisibilidade e ambiguidade da situação, pode-se procurar estabelecer melhor com o atleta o que é esperado que aconteça na situação em causa e o que é esperado exatamente que ele faça, antecipando, se possível, mais do que um curso de ação, para o caso da primeira solução não funcionar.

Quanto à perceção de importância, deve-se analisar de que modo a situação em causa é relevante para o atleta e se não existirá um desajustamento de expectativas que a torna 
exageradamente decisiva. Por vezes, usar uma estratégia como a formulação de objetivos (Latham \& Locke, 2007) representa uma boa solução para promover padrões de avaliação da atividade desportiva mais realistas e ajustados, diminuindo a tensão subsequente da exposição à situação de stress.

No caso dos processos de avaliação cognitiva, a informação obtida pode também ser muito relevante e decisiva para ajudar o atleta. Desde logo, ao nível primário (e eventualmente terciário), o psicólogo analisará se a situação de stress está a assumir um curso negativo (onde predominam a ameaça ou mesmo o prejuízo) ou positivo (onde predominam o desafio e o benefício). Além disso, nesta etapa, importa também que o psicólogo avalie as razões da situação estar a ser avaliada mais positivamente ou negativamente, uma vez que intervir sobre estas causas pode ajudar a resolver/controlar o problema. Ao nível secundário (e eventualmente quaternário), o psicólogo deverá treinar ou ajustar o melhor possível as estratégias de confronto do atleta para lidar o mais eficazmente possível com a fonte de stress. Neste caso, importa considerar até que ponto o atleta se sente capaz de lidar com o problema (potencial de confronto) e até que ponto sente que depende de si a resolução da situação (controle pessoal). No caso do potencial de confronto, a intervenção recairá essencialmente sobre o ajuste ou treino das melhores estratégias de confronto para lidar com a situação em causa. No caso do controle pessoal, a intervenção procurará essencialmente restabelecer a perceção de competência do atleta, analisando-se exatamente o quê na situação que pode ser concretizado atendendo às reais capacidades do atleta.

No que se refere às respostas à situação de stress, frequentemente é por aqui que o problema é apresentado pelo atleta ao psicólogo. Quando os processos de adaptação ao stress não decorrem favoravelmente, é comum os atletas abordarem o psicólogo com queixas de ansiedade, tensão física e até desmotivação face à atividade desportiva. E, também de modo algo frequente, a intervenção tende a recair sobre os sintomas e não tanto sobre as causas do problema. No entanto, com uma abordagem conceptual da que é apresentada neste trabalho, torna-se óbvia a relevância de compreender todo o processo de adaptação ao stress e abordar com o atleta o fator ou fatores que poderão estar na origem das respostas indesejáveis ao stress desportivo.

Finalmente, o grande objetivo da intervenção psicológica passa pela promoção do funcionamento humano positivo. A intervenção nos domínios que acabamos de apresentar poderá ser uma das melhores soluções para tornar a atividade desportiva numa experiência positiva, desafiadora e recompensadora para o atleta.

No que se refere à investigação, o maior desafio é captar a natureza transacional e interativa da adaptação ao stress, incluindo nas análises as variáveis descritas anteriormente. Desde logo, uma das premissas principais passa pela aceitação do papel mediador da avaliação cognitiva na relação estabelecida entre a situação de stress (i.e., fonte de stress) e o resultado final da adaptação (avaliada tanto do ponto de vista negativo como positivo). Um mediador dá-nos indicações acerca de como e porquê se dá uma relação causal entre duas variáveis, agindo como interveniente na relação entre uma variável independente (ex: stress) e uma variável dependente (ex: satisfação), recebendo assim a influência da primeira e influenciado a segunda (Baron \& Kenny, 1986). Existem múltiplas formas de organizar os modelos de análise, incluindo-se um ou mais mediadores (Hayes, 2009), pelo que os investigadores poderão partir de modelos mais simples (considerando "apenas" o papel mediador da avaliação cognitiva) até modelos mais complexos inserindo as respostas à situação de stress (ver Figura 2).

Adicionalmente, e tendo também em consideração o Modelo Interativo de Adaptação ao Stress, os investigadores poderão estar interessados em analisar o papel moderador de algumas variáveis situacionais e pessoais na relação entre a situação de stress e o resultado final da adaptação. Neste caso, entende-se por variável moderadora variáveis quantitativas, do tipo contínuo (ex: idade), ou qualitativas, do tipo nominal (ex: sexo), que podem influenciar a direção e/ou força da relação entre a variável independente e a variável dependente (Baron \& Kenny, 1986). Por exemplo, podemos aceitar que 
o processo de adaptação ao stress tem como variável central os processos de avaliação cognitiva, mas podemos assumir como hipótese que esta relação será mais forte consoante a experiência, medidas em anos, das pessoas na situação em causa.

Finalmente, e como refere Lazarus (2000c), a organização do estudo destas variáveis carece de planos de investigação longitudinais, efetuados com as mesmas pessoas sujeitas a uma ou mais situações de stress, de modo a conseguir-se identificar estruturas psicológicas (ex: traços de personalidade) e processos psicológicos (ex: avaliação cognitiva) inerentes à adaptação humana a situações de tensão e mudança.

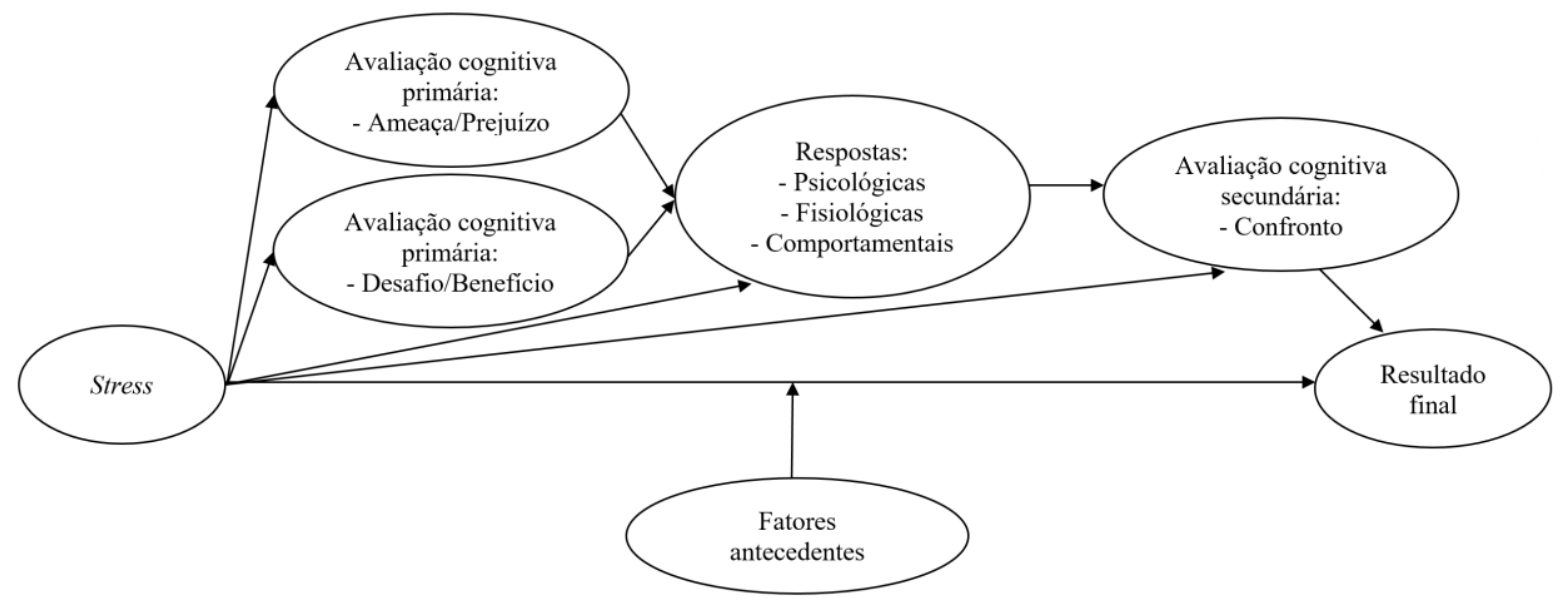

Figura 2. Relação entre as Variáveis do Modelo Interativo de Adaptação ao Stress

\section{Notas Finais}

Tal como referimos no início deste trabalho, é certo que os fatores psicológicos assumem um papel fundamental no modo como os atletas se adaptam às situações de stress no desporto e também é certo que estes mesmos fatores influenciem $\mathrm{o}$ rendimento final obtido nas competições. No entanto, é muito menos óbvio o modo como este processo de adaptação decorre e o modo como os diferentes fatores implicados nesta adaptação interagem e se influenciam mutuamente.

No entanto, a adaptação ocorre conduzindo no, final, a um resultado positivo ou negativo. Por isso, cabe à investigação desconstruir estes processos de adaptação mas não a um ponto que conduza a um entendimento parcelar e estanque dos fatores que influenciam a adaptação dos atletas aos seus contextos desportivos. Este foi o principal desafio deste trabalho: explorar, do ponto de vista conceptual, o modo como ocorre o processo de adaptação ao stress e propor, do ponto de vista metodológico, instrumentos que possam ajudar a este entendimento integrado e interativo do processo transacional estabelecido entre o indivíduo e a situação de stress. Apesar de temos efetuado esta reflexão a propósito do contexto desportivo, existem razões para crer que esta mesma análise possa ser aplicada a situações de exposição ao stress noutras atividades e situações. Aliás, esta troca de conhecimentos entre diferentes áreas de adaptação humana só poderá conduzir a um melhor conhecimento acerca dos fatores que influenciam a adaptação ao stress, explicando um dos grandes desafios do funcionamento humano: "máximo rendimento sob máxima pressão".

Agradecimentos:

Nada a declarar

\section{Conflito de Interesses:}

Nada a declarar.

Financiamento:
Este trabalho foi realizado no Centro de Investigação
em Psicologia (UID/PSI/01662/2013), Universidade
do Minho, e foi financeiramente suportado pela
Fundação para a Ciência e Tecnologia e pelo
Ministérios da Ciência, Tecnologia e Ensino Superior,
através de fundos nacionais, e co-financiado pelo
FEDER, através do COMPETE2020, no âmbito do
acordo Portugal 2020 (POCI-01-0145-FEDER-
007653).




\section{REFERÊNCIAS}

Balk, Y. A., Adriaanse, M. A., de Ridder, D. T. D., \& Evers, C. (2013). Coping under pressure: Employing emotion regulation strategies to enhance performance under pressure. Journal of Sport \& Exercise Psychology, 35, 408-418.

Baron, R. M., \& Kenny, D. A. (1986). The moderatormediator variable distinction in social psychological research: Conceptual, strategic, and statistical considerations. Journal of Personality and Social Psychology, 51 (6), 1173-1182.

Calmeiro, L., Tenenbaum, G., \& Eccles, D. W. (2014). Managing pressure: Patterns of appraisals and coping strategies of non-elite and elite athletes during competition. Journal of Sports Sciences, $32(19)$, 1813-1820. doi:10.1080/02640414.2014.922692.

Campbell, E., \& Jones, G. (2002). Sources of stress experienced by elite male wheelchair basketball players. Adapted Physical Activity Quarterly, 19, 8299.

Carver, C. S., \& Scheier, M. F. (1985). Selfconsciousness, expectancies, and the coping process. In T. Field, P. M. McCabe, \& N. Schneiderman (Org.), Stress and coping (pp. 305330). Hillsdale, NJ: Erlbaum.

Carver, C. S., Scheier, M. F., \& Weintraub, J. K. (1989). Assessing coping strategies: A theoretically based approach. Journal of Personality and Social Psychology, 56(2), 267-283.

Cox, R. H., Shannon, J. K., McGuire, R. T., \& McBride, A. (2010). Predicting subjective athletic performance from psychological skills after controlling for sex and sport. Journal of Sport Behavior, 33(2), 129-145.

Coyne, J. C., \& Racioppo, M. W. (2000). Never the twain shall meet? Closing the gap between coping research and clinical intervention research. American Psychologist, 55, 655-664.

Dugdale, J. R., Eklund, R. C., \& Gordon, S. (2002). Expected and unexpected stressors in major international competition: Appraisal, coping, and performance. The Sport Psychologist, 16, 20-33.

Endler, N. S., \& Parker, D. A. (1990). Multidimensional assessment of coping: A critical evaluation. Journal of Personality and Social Psychology, 58, 844-854.

Fletcher, D., \& Fletcher, J. (2005). A meta-model of stress, emotions and performance: Conceptual foundations, theoretical framework, and research directions [Abstract]. Journal of Sports Sciences, 23, 157-158.

Fletcher, D., \& Hanton, S. (2003). Sources of organizational stress in elite sports performers. The Sport Psychologist, 17(2), 175-195.

Fletcher, D., Hanton, S., \& Mellalieu, S. D. (2006). An organizational stress review: Conceptual and theoretical issues in competitive sport. In $\mathrm{S}$. Hanton \& S. D. Mellalieu (Org.), Literature reviews in sport psychology (pp. 321-374). Hauppauge NY: Nova Science.
Folkman, S., \& Lazarus, R. S. (1980). An analysis of coping in a middle-aged community sample. Journal of Health and Social Behavior, 21, 219-239.

Folkman, S., \& Lazarus, R. S. (1985). If it changes it must be a process: A study of emotion and coping during three stages of a college examination. Journal of Personality and Social Psychology, 48, 150170.

Folkman, S., \& Lazarus, R. S. (1988). Ways of Coping Questionnaire: Sampler set, manual, test booklet, scoring key. Redwood City, California: Consulting Psychologists Press.

Gomes, A. R. (2011). Adaptação humana em contextos desportivos: Contributos da teoria para a avaliação psicológica. Avaliação Psicológica, 10(1), 13-24.

Gomes, A. R. (2014). Positive human functioning in stress situations: An interactive proposal. In A. R. Gomes, R. Resende, \& A. Albuquerque (eds.), Positive human functioning from a multidimensional perspective: Promoting stress adaptation (Vol. 1, pp. 165-194). New York: Nova Science.

Hatzigeorgiadis, A., Zourbanos, N., Galanis, E., \& Theodorakis, Y. (2011). Self-talk and sports performance: A meta-analysis. Perspectives on Psychological Science, 6, 348-356. doi.org/10.1177/1745691611413136.

Hayes, A. F. (2009). Beyond Baron and Kenny: Statistical mediation analysis in the New Millennium. Communication Monographs, 76(4), 408-420.

Jones, M. V., Lane, A. M., Bray, S. R., Uphill, M., \& Catlin, J. (2005). Development and validation of the Sport Emotion Questionnaire. Journal of Sport E Exercise Psychology, 27(4), 407-431.

Kaiseler, M., Polman, R. C. J., \& Nicholls, A. R. (2013). Gender differences in stress, appraisal, and coping during golf putting. International Journal of Sport and Exercise Psychology, 11 (3), 258-272. doi: 10.1080/1612197X.2013.749004.

Latham, G. P., \& Locke, E. A. (2007). New developments in and directions for goal-setting research. European Psychologist, 12 (4), 290-300.

Lazarus, R. S. (1991). Emotion and adaptation. New York: Oxford University Press.

Lazarus, R. S. (1995). Psychological stress in the workplace. In R. Crandall \& P. L. Perrewé (Eds.), Occupational stress: A handbook (pp. 3-14). Washington, DC: Taylor \& Francis.

Lazarus, R. S. (1999). Stress and emotion: A new synthesis. New York: Springer.

Lazarus, R. S. (2000a). Cognitive motivational relational theory of emotion. In Y. L. Hanin (Org.), Emotions in sport (pp. 39-64). Champaign, IL: Human Kinetics.

Lazarus, R. S. (2000b). How emotions influence performance in competitive sports. The Sport Psychologist, 14, 229-252.

Lazarus, R. S. (2000c). Toward better research on stress and coping. American Psychologist, 55(6), 665-673. 
Lazarus, R. S., \& Folkman, S. (1984). Stress, appraisal, and coping. New York: Springer.

MacNamara, A., Button, A., \& Collins, D. (2010). The role of psychological characteristics in facilitating the pathway to elite performance. Part 1: Identifying mental skills and behaviors. The Sport Psychologist, 24, 52-73.

McKay, J., Niven, A. G., Lavallee, D., \& White, A. (2008). Sources of strain among UK elite athletes. The Sport Psychologist, 22, 143-163.

Nicholls, A. R. (2007). A longitudinal phenomenological analysis of coping effectiveness among Scottish international adolescent golfers. European Journal of Sport Science, 7(3), 169-178.

Nicholls, A. R., Levy, A. R., Jones, L., Rengamani, M., \& Polman, R. C. J. (2011). An exploration of the two-factor schematization of relational meaning and emotions among professional rugby union players. International Journal of Sport and Exercise Psychology, 9, 78-91. doi:10.1080/1612197X.2011.563128.

Nicholls, A. R., Perry, J. L., \& Calmeiro, L. (2014). Precompetitive achievement goals, stress appraisals, emotions, and coping among athletes. Journal of Sport and Exercise Psychology, 36, 433445.

Nicholls, A. R., \& Polman, R. C. J. (2007). Coping in sport: A systematic review. Journal of Sport Sciences, 25(1), 11-31.

Nicholls, A. R., Polman, R. C. J., Morley, D., \& Taylor, N. J. (2009). Coping and coping effectiveness in relation to a competitive sport event: Pubertal status, chronological age, and gender among adolescent athletes. Journal of Sport and Exercise Psychology, 31 (3), 299-317.
Noblet, A. J., \& Gifford, S. M. (2002). The sources of stress experienced by professional Australian footballers. Journal of Applied Sport Psychology, 14, 1-13.

Pensgaard, A. M., \& Duda, J. L. (2002). "If we work hard we can do it!" A tale from an Olympic (gold) medallist. Journal of Applied Sport Psychology, 14(3), 219-236.

Rathschlag, M., \& Memmert, D. (2015). Self-generated emotions and their influence on sprint performance: An investigation of happiness and anxiety. Journal of Applied Sport Psychology, 27(2), 186-199. doi: 10.1080/10413200.2014.974783.

Rotella, R. J., \& Lerner, J .D. (1993). Responding to competitive pressure. In R. N. Singer, M. Murphey, \& L. K. Tennant (Org.), Handbook of research on sport psychology (528-541). New York: Macmillan.

Scheier, M. F., \& Carver, C. S. (1988). A model of behavioural self-regulation: Translating intention into action. In L. Berkowitz (Org.), Advances in experimental social psychology (Vol. 21, pp. 303346). New York: Academic Press.

Shirom, A., Gilboa, S., Fried, Y., \& Cooper, C. L. (2008). Gender, age and tenure as moderators of work-related stressors' relationships with job performance: A meta-analysis. Human Relations, 61(10), 1371-1398.

Thatcher, J., \& Day, M. C. (2008). Re-appraising stress appraisals: The underlying properties of stress in sport. Psychology of Sport and Exercise, 9, 318-335.

Wolf, S. A., Evans, M. B., Laborde, S., \& Kleinert, J. (2015). Assessing what generates precompetitive emotions: Development of the precompetitive appraisal measure. Journal of Sports Sciences, 33(6), 579-587. doi: 10.1080/02640414.2014.951873. 